
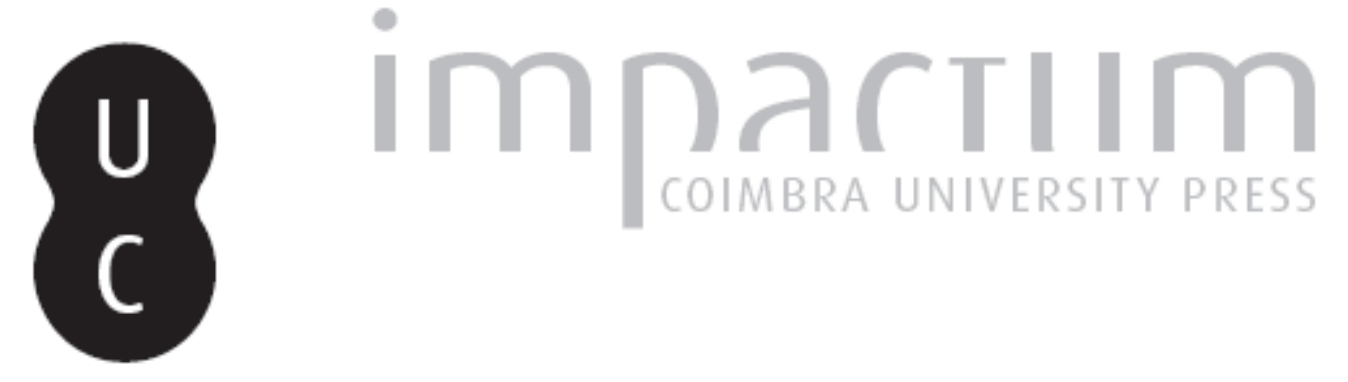

\title{
Vox Mediarama: Um Audioguia
}

Autor(es): $\quad$ Neves, Nuno Miguel; Schwäbl, Tiago

Publicado por: Centro de Literatura Portuguesa; Imprensa da Universidade de Coimbra

URL persistente:

URI:http://hdl.handle.net/10316.2/43619

DOI:

DOI:https://doi.org/10.14195/2182-8830_5-1_5

Accessed : $\quad$ 26-Apr-2023 15:43:58

A navegação consulta e descarregamento dos títulos inseridos nas Bibliotecas Digitais UC Digitalis, UC Pombalina e UC Impactum, pressupõem a aceitação plena e sem reservas dos Termos e Condições de Uso destas Bibliotecas Digitais, disponíveis em https://digitalis.uc.pt/pt-pt/termos.

Conforme exposto nos referidos Termos e Condições de Uso, o descarregamento de títulos de acesso restrito requer uma licença válida de autorização devendo o utilizador aceder ao(s) documento(s) a partir de um endereço de IP da instituição detentora da supramencionada licença.

Ao utilizador é apenas permitido o descarregamento para uso pessoal, pelo que o emprego do(s) título(s) descarregado(s) para outro fim, designadamente comercial, carece de autorização do respetivo autor ou editor da obra.

Na medida em que todas as obras da UC Digitalis se encontram protegidas pelo Código do Direito de Autor e Direitos Conexos e demais legislação aplicável, toda a cópia, parcial ou total, deste documento, nos casos em que é legalmente admitida, deverá conter ou fazer-se acompanhar por este aviso.

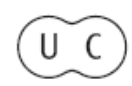




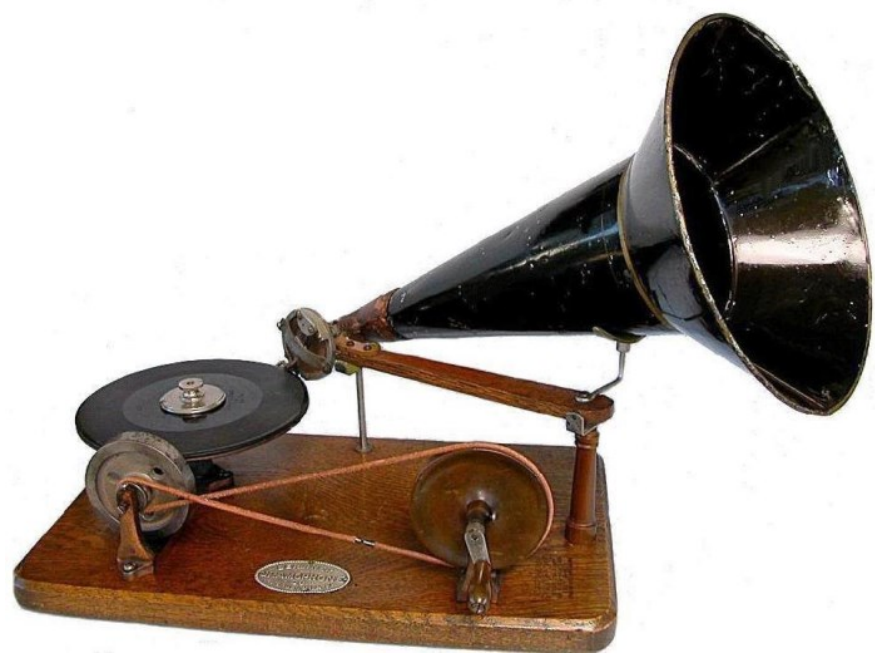

ช2

త్ర

త్ర్త్ర

(⿻)

घ)

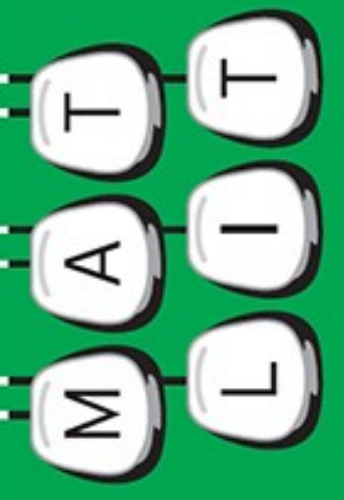

Vol. 5.1 (2017)

ISSN 2182-8830

'Vox Media: O Som na Literatura'

Osvaldo Manuel Silvestre e

Felipe Cussen (orgs.) 


\author{
Vox Mediarama: Um Audioguia \\ Nuno Miguel NeVES \\ CLP | Universidade de Coimbra \\ Bolseiro da FCT \\ TIAGO SCHWÄBL \\ CLP | Universidade de Coimbra
}

\title{
1. Oprojeto Vox Media
}

Vox Media: O Som na Literatura é um projeto de investigação do grupo "Mediação Digital e Materialidades da Literatura" associado ao Centro de Literatura Portuguesa da Faculdade de Letras da Universidade de Coimbra, e constitui o foco do presente número da revista Materialidades da Literatura. Da história deste projeto, cujos objetivos passam pela investigação da relação entre a inscrição literária e a fonografia, e pela análise da presença da voz humana e do universo sonoro na experiência literária, fazem já parte um colóquio intitulado Vox Media: O Som na Literatura, realizado em novembro de 2015, que contou com a presença e participação dos vários investigadores associados ao projeto; a conferência e performance da artista sonora italiana Alessandra Eramo, em abril de 2016, a criação e manutenção de um site e também de uma newsletter intitulada Voxletter, de periodicidade ainda irregular mas que pretende, a curto prazo, tornar-se mensal; e, por fim, a participação dos seus investigadores em diversos encontros científicos de caráter nacional e internacional. É também enquanto membros deste projeto que desenvolvemos as nossas teses de doutoramento: "Vox Ex Machina: A Poesia Sonora no Século XXI", de Nuno Miguel Neves, e "shrrshrrsh: Questões de notação na poesia sonora", de Tiago Schwäbl. Mais recentemente, o projeto adicionou ao seu currículo a realização de um colóquio multidisciplinar dedicado a António Variações, realizado na Faculdade de Letras da Universidade de Coimbra a 7 e 8 de dezembro de 2017.

Como editores da secção de Mediarama deste número, interessava-nos, sobretudo, dar conta de um conjunto de possibilidades que não se esgotam, necessariamente, na Poesia Sonora, a nossa área de investigação, e explorar também, embora em menor medida, formas de criação artística. A presente secção assume-se assim, de alguma forma, como uma outra face de um trabalho que temos vindo a realizar no âmbito do debate, promoção e divulgação da Poesia Sonora, e do Som na Literatura lato sensu, e que tem o seu rosto mais visível no programa semanal Hipoglote, transmitido nos 107.9 FM da RU( - Rádio Universidade de Coimbra. Da autoria de Tiago Schwäbl, estreou 
a 21 de julho de 2016, com uma entrevista a Miguel Azguime, e vai já na sua 72. ${ }^{a}$ edição. Ao longo destas 72 horas houve já espaço para entrevista (Clive Fencott, Américo Rodrigues, Juan Angel Italiano, Anna Serra, entre tantos outros e outras), edições temáticas (Poesia Sonora da América Latina, a obra de Demetrios Stratos, etc...) bem como programas de âmbito mais genérico que permitem desenhar uma perspetiva alargada não só da Poesia Sonora mas, também, daquilo que poderíamos designar genericamente, seguindo uma sugestão de Steve McCaffery, como uma Poética das Vocalidades (McCaffery and Minarelli 2014).

O projeto, que agora se materializa neste número da revista Materialidades da Literatura dedicado ao Som, constitui um gesto representativo daquela que pode ser considerada como uma viragem em direção às questões sonoras e que, nos últimos anos, tem vindo progressivamente a ganhar espaço no campo das Humanidades. Neste sentido, podem destacar-se, sem prejuízo de outras e sublinhando sempre a profusão de trabalhos realizados e publicados, obras que privilegiam uma perspetiva historicista (Lovell 2015; Denning 2015; Scales 2016; Curtin 2016); outras que colocam em evidência a relação entre o mundo sonoro e a Literatura (Rubery 2011; Perloff \& Dworkin 2009); também obras que exploram novos formatos e artefactos na sua relação com questões culturais (Bijsterveld \& Dijck 2009; Sterne 2012). Estas são apenas algumas referências num campo de produção científica em franca expansão e representam uma nova tendência que vai para além da Literatura ao cruzar áreas disciplinares como a Musicologia, o Estudo dos Média ou a Sociologia, e a partir da qual se cruzam problemáticas associadas à tecnologia e à produção cultural lato sensu. Foi de resto com o objetivo de contemplar esta multiplicidade de perspetivas que se pediu, na Convocatória para Sons, "composições que se enquadrem, quer estética, quer conceptualmente, no âmbito da poesia sonora, composição texto-som, sound art, e práticas congéneres." O presente volume da MATLIT, e esta secção "Mediarama", define-se pois pela abertura a um leque vasto de práticas sonoras, a partir das quais esperamos poder desenhar um quadro panorâmico das possíveis relações entre Som e Literatura.

É no mesmo sentido que a Convocatória para Sons reforça a ideia da "relevância de um estudo das diferentes formas de inscrição material para uma versão mais completa, simultaneamente moderna e arcaica, de literatura, que não se esgote na ideia de texto como sendo apenas 'letras impressas em papel"'. Este afastamento do papel, e os efeitos de desestabilização que esse afastamento parece promover, não é novo e remonta já às vanguardas do início do século XX embora tenha vindo a ser, desde então, permanentemente reconfigurado e relocalizado pelos desenvolvimentos tecnológicos, com consequências profundas e visíveis na produção poética e na própria voz (Neumark 2017; LaBelle 2014; Smith 2008). Não estamos inteiramente convencidos de que a Teoria Literária tenha acompanhado estes processos da mesma forma e com o mesmo entusiasmo com que acompanhou outros na 
área da Literatura, mais próximos das formas e géneros tradicionais, nem que tenha conseguido abandonar por completo um conjunto de pressupostas que colonizam ainda o discurso académico sobre a relação entre Literatura e Oralidade (Aktories 2008). A nossa proposta vai por isso no sentido da observação destes fenómenos a partir do campo disciplinar da Teoria Literária ou, para recuperar uma expressão que nos parece bastante feliz de Susana Aktories, a partir da "trincheira disciplinar da Literatura" (Aktories 2008: 375).

As autoras e autores, cujas obras sonoras aqui se apresentam, provêm de diferentes áreas de estudo, de investigação e de trabalho, o que teve consequências óbvias na tipologia das obras recebidas. Estabelecemos por isso uma tipologia imaginária (como o são todas em certa medida, é certo) com três eixos: 1) leitura fonética/ voz solo; 2) voz + eletroacústica/ colagem/ composição texto-som; 3) música/ soundart/ soundscape. Temos consciência de que esta tipologia, e a distribuição que sobre ela se fez das obras publicadas, é problemática e questionável. Contudo, temos também consciência de que, em ambiente académico, não poderia ser de outra forma.

\section{Leitura fonética/ voz solo}

A primeira categoria - 1) leitura fonética/ voz solo — inicia-se com adver Cidade (voz e papel), de Américo Rodrigues, uma peça original criada para integrar este número da revista, que assume, como o próprio nome parece indicar, a reflexão "sobre o lugar do poeta na praça de jorna" (ver sinopse). Para se compreender na totalidade esta adverCidade, deve ter-se em conta o percurso de Américo Rodrigues e a sua relação com os "poderes" autárquicos da sua cidade natal, a Guarda. Na véspera da apresentação do seu último álbum, 'Parlatório', Américo Rodrigues foi afastado das funções de coordenador da Biblioteca Municipal Eduardo Lourenço. Nada de novo para o autor da Guarda que tinha passado pelo mesmo processo em 2013 quando era diretor do Teatro Municipal da Guarda (TMG). A qualidade do seu trabalho como programador artístico tem-lhe valido a criação de alguns anticorpos, resultado do trabalho inovador que realiza (tão inovador que Eduardo Lourenço se referiu ao TMG como um “ovni na Guarda”, expressão que deu origem ao título da entrevista que realizámos a Américo Rodrigues e que pode ser ouvida aqui). ${ }^{1}$ Com efeito, grande comoção assinala invariavelmente a sua passagem, embora sofra, no ápice do seu voo, os dissabores alheios da inveja. Mas não será essa adverCidade que impedirá Américo Rodrigues - bem pelo contrário, todas as palavras serão fracas perante a força vocal de que o autor se mostra sempre capaz.

${ }^{1}$ A entrevista termina com algumas palavras que assumem hoje um caráter premonitório. Diz Américo Rodrigues: "há um ritmo tal de acontecimentos que poderá estar a acontecer a mesma coisa que aconteceu no Teatro. Poderá estar a acontecer...” 
Intima Mente, a peça realizada por Alfredo Costa Monteiro ${ }^{2}$ a convite dos editores, é uma peça na qual a lógica de desconstrução fonética ao campo semântico é operada por um intensivo trabalho de introdução de sonoridades eletrónicas. A obra consiste numa jogada manifestamente aliterativa, combinando rimas em torno da palavra 'intimamente', numa atmosfera pleonasticamente reservada de uma mente que é em si doente e mente, iminentemente. As palavras preservam a sua integridade, não se desfazendo em som ou ruído, os seus blocos sobressaem eminentes sobre um fundo eletrónico a golpes de ruído difuso, com efeitos de eco subtis que acompanham o trajeto de uma voz sombria e sussurrante, todavia clara, nunca dominada pela tecnologia, embora essa tensão/possibilidade esteja presente, no percurso mental a que a eletrónica dá chão virtual na imaginação espacial proporcionada pela alternância entre distanciação e aproximação dessa voz off mental. ${ }^{3}$

the fisted neck, de John M. Bennett, estabelece uma leitura que desliza do sentido realístico-descritivo à aliteração irracional e congestionada de uma palavra em súbita repetição ou reversão. $O$ reforço do obstáculo à leitura como afirmação de possibilidades ganha força mastigante na livre circulação da fala, dentro e fora da boca, à frente e atrás das letras.

Galaxia vocálica é a peça que nos chega pela voz de Juan Angel Italiano. O poeta uruguaio, residente em Montevideo, é um dos mais acarinhados poetas sonoros sul-americanos, com um extraordinário trajeto que extravasa a produção sonora e se estende ao design das capas dos próprios álbuns, aos diversos blogs que edita (aqui e aqui) e à dedicação sem fronteiras à poesia sonora (a entrevista ao Hipoglote pode ser ouvida aqui e aqui). ${ }^{4} \mathrm{O}$ foco vocálico desta faixa apresenta-nos a ausência das consoantes, a par da surpreendente mas óbvia conclusão acerca do marco definidor do esqueleto dos significantes. Nos primórdios da escrita, um sistema de vogais facilitava a leitura ao longo dos tempos em scriptura continua até que a gradual introdução da pontuação as enquadrou nas palavras devidas. Um outro aspeto a ter em conta é a ideia de que as vogais são as letras que não possuem restrições físicas na sua formulação: nem lábios, nem dentes, nem língua. A boca atua como uma dupla caixa vocálica, enunciando os formantes que lhes dão corpo e definição. As vogais em si podem ser múltiplas palavras desconhecidas os seus restos não nos conduzem a nenhum discurso, a nenhum puzzle que, uma vez montado, nos levasse à descoberta de uma nova gramática. Aqui

\footnotetext{
$2 \mathrm{Um}$ dos poucos portugueses a trabalhar continuadamente poesia sonora e, ainda assim, fora de portas, em Barcelona. Foi também entrevistado para o Hipoglote e pode ser ouvido aqui.

${ }^{3}$ Sublinhe-se que, embora com diferenças formais significativas, Américo Rodrigues e Alfredo Costa Monteiro são os únicos autores portugueses associados à Poesia Sonora a trabalhar neste registo de forma sistemática e continuada.

4 Tivemos oportunidade de conversar com Felipe Cussen, aquando da sua conferência em Coimbra, que se referia carinhosamente a Juan Angel Italiano como a UbuWeb da América Latina devido ao intenso trabalho de arquivo - sonoro e textual — que este tem vindo a realizar e que disponibiliza nas suas Ediciones del Cementerio.
} 
entrecortadas, não constituem sequer canto: são partes concretas de algo que não pode simplesmente ser descodificado numa frase ou discurso. A planície do ruído estático expande a planície refletora das potenciais galáxias vocálicas.

É também da América Latina que nos chega Luis Bravo e os seus 10 minutos de ronquidos y lluvia. Sons aspirados e expirados, roncos vocais que se insinuam na substância fónica dos ruídos bucais, esta é das faixas que mais se agarram ao âmago corporal, afastando-se da vibração das cordas vocais e de potenciais frequências com altura definida. Sons adjacentes aos fenómenos quotidianos do corpo tomam aqui corpo numa cavidade onde a função comunicativa oral partilha o espaço da linguagem com outras atividades não menos essenciais - comer, beber, bochechar, bocejar, tremer, gritar, assobiar, mastigar, ranger, etc. - , como bem se comprova nesta faixa. Em fundo, quase impercetível, a chuva cadencia o ronco que associamos ao mais absorto dos descansos, respiração cava e contínua que dificilmente poderia conter voz, embora ela apareça no sono, por reflexo do pensamento.

Ainda neste registo, Shatoe, de AG Davis. A introdução triunfante é a de uma leitura "karawanesca", embora sem a pompa e circunstância da impressão gótica dos versos de Hugo Ball. Shatoe apresenta a gravação de um solo surrealinguístico e borbulhante ao estilo naif de uma conversa pré-infantil, a imitação declarada de uma língua estrangeira da qual não dominamos sintaxe mas cuja hermenêutica é clara, ou diabruras vocais meio-falantes, sussurrantes ou explosivas - jogos a que nenhum de nós foi alguma vez alheio. Elementos vocais de (de)formação vocal são testados no enquadramento físico dos formantes vocais e dos canais próprios de afunilamento e especificação dos sons bucais humanos. A exploração da pseudo-confiança lexical leva-nos pelos caminhos fluidos de uma conversa, e a semelhança com o linguajar persiste mesmo quando tentamos afastar-nos dela; não há aqui anulação da linguagem, apenas o desvio para um trilho paralelo tornado inalcançável no significado; o rasto narrativo perde-se em meandros não-identificáveis; o discorrimento sem pausas parodia uma locução de desenho animado e a irrealidade de uma proposta que reflete a própria impossibilidade de extenuação da linguagem.

Por último, no âmbito desta primeira categoria de leitura fonética/ voz solo, o trabalho de Álvaro Seiça, As valas abertas. A faixa promove, como o fazem de modos diferentes outras obras deste conjunto, uma reflexão sobre o próprio texto e sobre o próprio código de escrita e/ou de leitura. A leitura de um texto (em português) intercalado com leitura de código-fonte, a voz do leitor como elemento aglutinador que, indiferente ao tipo de texto, opera uma leitura que, aparentemente maquínica e cega à diferenciação dos elementos textuais, ao seu sentido operativo, se acondiciona ao fluxo vocal contínuo. Exercício (já) clássico na fronteira entre os elementos que tradicionalmente pertencem a um meio e são a posteriori reproduzidos em termos que não aqueles para os quais foram produzidos, aproveitando a lacuna ou vala 
aberta que a deslocação entre sistemas origina, a sua reprodução-recuperação provoca o incontornável desfasamento na receção da informação e do ambiente lexical potencialmente antecipado pelo leitor. O contrário é igualmente válido e provoca quase o mesmo efeito: uma máquina lendo texto não operativo. No entanto, existe aqui alguma descodificação, a sujeição a um certo tipo de convenção que identifica e discerne formas de leitura de símbolos convencionalmente não fonéticos.

\section{Voz + eletroacústica/ colagem/ composição texto-som}

A segunda categoria, desta tipologia improvisada e hipotética que definimos para organização desta secção, é a da Voz + eletroacústica/ colagem/ composição texto-som. Narrative Currents é uma obra conjunta de Ryan Wade Ruehlen e de Mark Amerika. Apreensão dos sons da realidade — ou concretos - em obra eletroacústica, o mundo como repositório sonoro, aqui a envolvência é a da sound art, em explicação documental autorreferencial, num diálogo sobre paisagem sonora sobreposto a uma paisagem sonora, possível circuito exterior chuvoso justapondo-se a uma conversa de aquário seco com água em seu redor. Todavia, a adjacência sonora nem sempre evita a separação entre o lugar da reprodução e o da gravação, espaços e minudências assíncronas ainda, e sempre, por resolver.

John F. Barber traz-nos MATLIT v.5. De notar que não é a primeira vez que nos cruzamos com John Barber e com o seu trabalho. Tivemos já o prazer de o entrevistar para o Hipoglote (a entrevista pode ser ouvida aqui) e tivemos oportunidade de ouvir e ver a instalação multimédia Remembering the Dead, durante a Conferência da Irish Sound, Science and Technology Association, realizada em Derry, Irlanda do Norte, em 2016. A qualidade das suas montagens sonoras, sempre irrepreensíveis e bem-humoradas, é aqui ponto de partida para uma travessia na senda da literatura digital através de testemunhos e contrapontos, do canto lírico à entrevista casual num foyer, à resposta automática de um software e à decomposição vocal da própria palavra e-literature. O fundo folk-aulódico contrasta com o seu antípoda digital, os sons de notificações sintetizadas num loop que facilmente desemboca em leitura de poesia, discussões radiofónicas ou simples estórias de vozes cativantes e claras que nos convidam a mais uma história. Dez minutos de (des)sintonização de um potencial arquivo que nos baralha o tempo, da música a números a síntese de voz, confrontos entre termos não graváveis e realidades sonoras cuja presença nos é apresentada em direto e em primeira mão; viagens a vários tempos e sons, a argumentações que acarretam o mundo e a espaços vazios de qualquer justificação. A grande lição desta faixa é talvez a da total coexistência.

Like a Letter, You, a obra de Jessica Barness e Vince Giles, chega-nos como registo da descrição de um processo: instruções para o uso de um novo 
aparelho, conclusões de um estudo científico, voz off de um documentário. A locução fluída e explicativa de operações interativas sofre por sua vez a interação de sinalizações sonoras que (sobre)pontuam o discurso académico. Ondulados rap, drum and bass sintético, imitações humanas de sons mecânicos e imitações artificiais de vozes humanas. Imagine-se o desfolhar de um powerpoint perante uma plateia de autómatos indiferentes às explicações de racionalizações humanas sobre correspondência escrita; as conclusões são irrelevantes, a vida está no gadget, não na informação. A apresentação de um processo de interação com a correspondência escrita confronta-se de forma nua perante uma sobreposição pouco colaborativa com a voz que a explica. Talvez seja essa a sua única riqueza: a interferência.

Télémaque, de Sandrine Deumier e Philippe Lamy, coloca em evidência uma voz feminina que providencia indicações acerca do estado das coisas e dos fenómenos, termos técnicos que preparam e abrangem a envolvência do software numa mistura de emoções que paradoxalmente reafirmam a $f(r)$ icção científica. Curiosamente, esta voz não é sintetizada, mas antes a gravação de uma voz humana associada, auditiva e tematicamente, a um meio robótico; a atração mora na singularidade da hipotética afinidade entre uma máquina e um ser-humano. Obra de pendor eletrónico, a autonomia vocal e fantasmagórica de um autómato do futuro remete-nos para possibilidades que só verão a luz da sua concretização no presente da sua reprodução sonora.

Ryan LaLiberty traz-nos Reading Thoreau in Another's Voice Reading Thoreau, leitura que a tecnologia permite sobreposta na própria voz, atropelando-se o fio de uma descrição no fio de outra, vozes que progressivamente vão sendo interrompidas pela eletricidade e pela alteração-obliteração do registo vocal através da programação de parâmetros de um software digital: os efeitos impõem-se lentamente ao discurso, as vozes não mais são objeto de compreensão ou acompanhamento auditivo — os ruídos ganham presença crescente na energia de loops saltitantes. Reformula-se implícita e inevitável a questão da presença ou ausência da voz no panorama tecnológico da poesia sonora.

Umetnost Gubljenja é a peça de Vladimir Vladda Miloykovitch. Nesta faixa a voz faz parte de uma cadência que a excede na composição e na abstrata marcação de sinais de espera onde não há espaço para o crack da máquina. Espaços (paraísos?) artificiais da linguagem, lugares de repetição insuportável e impossível, desvios mecanizados da voz que se transformam em loops maquínicos que só a tecnologia consegue sustentar. Retoma-se a questão da importância ou não da presença/ ausência da voz nas obras trabalhadas no âmbito eletroacústico, ou seja, formato onde a voz é apenas mais uma fonte sonora indiferenciada e congelada nos seus atributos. Como escreveu Felipe Cussen: "Quise grabar un disco de poesía sonora, pero me salió música electrónica” (Cussen 2014). 


\section{Música/ soundart/ soundscape}

A terceira e última categoria pode ser designada como música/ soundart/ soundscape. Incluímos nesta categoria duas obras. A primeira é Emma Soundscape, de Sara Pinheiro. Composta como parte de uma instalação em que se incluíam elementos de outra natureza, mas que pode perfeitamente existir de forma autónoma como aqui se prova, eis mais uma paisagem sonora para narrativa bem precisa e contextualizada, em formato audio walk. $O$ ouvinte acompanha e procura avidamente reconhecer e completar todos os indícios deixados/ registados. A visualização abre-se de forma definida. Todo o cenário foi já imaginado e todo o contexto desta história é familiar. Mesmo aqueles sons que não conseguimos reconhecer tomam forma perante os nossos olhos fechados. Já por ali passámos, de certeza.

O segundo trabalho é Language Has No Positive Terms, de David PrescottSteed. A faixa transporta-nos para uma atmosfera dub onírica, a lembrar Black Sifichi, em preenchimento harmónico onde a presença vocal emerge apenas no distanciamento e na profundidade que as frequências mais baixas lhe proporcionam. Este arrastamento e distorção xamânicos da voz supera-nos emocional e culturalmente para algo que nunca foi linguagem. Os resquícios vocais escassos e as aproximações a espaços de potencial não-linguístico, não comunicativo, marcam a cópia heliográfica de estruturas liminares da voz instrumental.

Estes três eixos apresentam um conjunto de outras obras que mobilizam diferentes recursos sonoros, verbais ou não, e diferentes técnicas e estratégias de reconfiguração do texto, com graus muito variados de trabalho de produção. O cruzamento de estilos, recursos sonoros, e trabalho de produção cria uma complexa rede de relações entre estilos de composição e géneros artísticos e permite colocar algo em evidência. Referimo-nos à demonstração da porosidade das fronteiras, no que diz respeito à questão dos géneros artísticos e literários, e no que isso permite para um debate alargado sobre as particularidades e sobre as diferenças dos diferentes tipos de registos e de composição.

Uma ideia de Literatura que tenha em consideração as questões sonoras é ainda, apesar de esforços nos últimos anos para que a situação se altere, uma questão recente. Não faria por isso sentido um volume dedicado ao Som na Literatura sem Voz e que não trouxesse consigo hipóteses desse trabalho sonoro cujos pressupostos teóricos aqui se exploram e desenvolvem na secção temática. Propomos por isso, enquanto editores desta secção, 15 peças para as quais pedimos uma audição atenta e esperamos que elas possam, mais do que responder a dúvidas e/ou fornecer respostas, colocar novas questões: De que forma se constituem, em termos sonoros, as manifestações literárias atuais? Podemos definir um paradigma contemporâneo de uma literatura sonora? A que soa, afinal, a contemporaneidade, como soa(m), afinal, a(s) Literatura(s)? 


\section{Referências}

AKTORIES, Susana González (2008). "Poesía Sonora, Arte Sonoro: Un Acercamiento a Sus Procesos de Semiosis.” Acta Poetica, 29.2: 375-92.

BIJSTERVELD, Karin, and José van Dijck, eds. (2009). Sound Souvenirs: Audio Technologies, Memory and Cultural Practices. Amsterdam: Amsterdam University Press.

CUSSEN, Felipe (2014). "Quise grabar un disco de poesía sonora, pero me salió música electrónica." CECLI - Centro de Estudios de Cosas Lindas e Inútiles. 13 Jan 2018.

http://ceclirevista.wordpress.com/2014/07/23/quise-grabar-un-discode-poesia-sonora-pero-me-salio-musica-electronica/

CURTIN, Adrian (2016). Avant-Garde Theatre Sound: Staging Sonic Modernity. Basingstoke: Palgrave Macmillan.

DENNING, Michael (2015). Noise Uprising: The Audiopolitics of a World Musical Revolution. London: Verso.

LABELLE, Brandon (2014). Lexicon of the Mouth: Poetics and Politics of Voice and the Oral Imaginary. London: A\&C Black/ Bloomsbury.

LOVELL, Stephen (2015). Russia in the Microphone Age: A History of Soviet Radio, 1919-1970. Oxford: Oxford University Press.

McCAFFERY, Steve, and Enzo Minarelli (2014). "Steve McCaffery." As Razões da Voz: Entrevistas com Protagonistas da Poesia Sonora no Século XX, Londrina: EDUEL. 144-62.

NEUMARK, Norie (2017). Voicetracks: Attuning to Voice in Media, and the Arts. Cambridge, MA: The MIT Press.

PERLOFF, Marjorie, and Craig Douglas Dworkin, eds. (2009). The Sound of Poetry, the Poetry of Sound. Chicago: The University of Chicago Press.

RUBERY, Matthew, ed. (2011). Audiobooks, Literature, and Sound Studies. London: Routledge.

SCALES, Rebecca (2016). Radio and the Politics of Sound in Interwar France, 1921 1939. Cambridge: Cambridge University Press.

SMITH, Jacob (2008). Vocal Tracks: Performance and Sound Media. Los Angeles, CA: University of California Press.

STERNE, Jonathan (2012). MP3: The Meaning of a Format. Durham, NC: Duke University Press.

(C) 2017 Nuno Miguel Neves e Tiago Schwäbl. Licensed under the Creative Commons Attribution-NoncommercialNo Derivative Works 4.0 International (CC BY-NC-ND 4.0). 